\title{
Prospects and problems of intellectualization of electric power systems in Mongolia
}

\author{
Bat-Erdene B. ${ }^{2}$, Batmunh S. ${ }^{l}$, Nikolai Voropai $^{3 *}$, Bat-Undral B. ${ }^{l}$ and Enhtur E. ${ }^{2}$ \\ ${ }^{1}$ Mongol State University of Sciences and Technologies, Ulan-Bator, Mongolia \\ ${ }^{2}$ Moscow Energy Institute "Research University", Moscow, Russia \\ ${ }^{3}$ Melentiev Energy Systems Institute, Siberian Branch of Russian Academy of Sciences, Irkutsk, Russia
}

\begin{abstract}
Status and prospects of electric power systems (EPSs) development in Mongolia are presented. Directions and peculiarities of EPS intellectualization activity in centralized and local RPSs are suggested.
\end{abstract}

\section{Introduction}

Principles and directions for development of the energy sector and electric power systems (EPS) in Mongolia are in the focus of many studies both within the fuel and energy complex of the country (including large-scale development of renewable energy sources), and within the concept of interconnection of standalone EPS and construction of Single EPS in the country, as well as considering participation of Mongolia in the inter-state cooperation of Northeast Asia countries on formation of Interstate Power Grid (IPG) [1-5].

Technological infrastructure of present-day EPS in Mongolia is characterized by complexity and includes a large number of stand-alone but interrelated on-line technical elements within the infrastructure systems that produce, transmit and distribute electric power to ensure its reliable supply of required quality to consumers. Requirements of consumers to power supply reliability and to power quality are currently much higher due to digitalization and intellectualization of their production processes.

The paper gives brief characteristic of the state-ofthe-art and prospects for development of the energy sector and EPS in Mongolia, analyzes directions and peculiarities of EPS intellectualization with account of their specific features, and discusses problems of largescale use of intellectual technologies for controlling the operation of future EPS of Mongolia.

\section{Status and prospects of EPS development in Mongolia}

Energy sector and EPS in Mongolia are currently presented and in the perspective will be presented by two directions:

- Centralized EPS in the zones of centralized power supply;

- Microgrids for power supply of islanded power consumers.

In the group of centralized EPS there are five independent energy systems in operation (Fig. 1) with the corresponding installed capacity, namely [1-5]:

1. Central EPS (CEPS) - $1250 \mathrm{MW}$;

2. Western EPS (WEPS) - $12 \mathrm{MW}$;

3. Sothern EES (SEPS) - $77 \mathrm{MW}$;

4. Altay- Uliastai EPS (AUEPS) - $11 \mathrm{MW}$;

5. Eastern EPS (EEPS) - $36 \mathrm{MW}$.

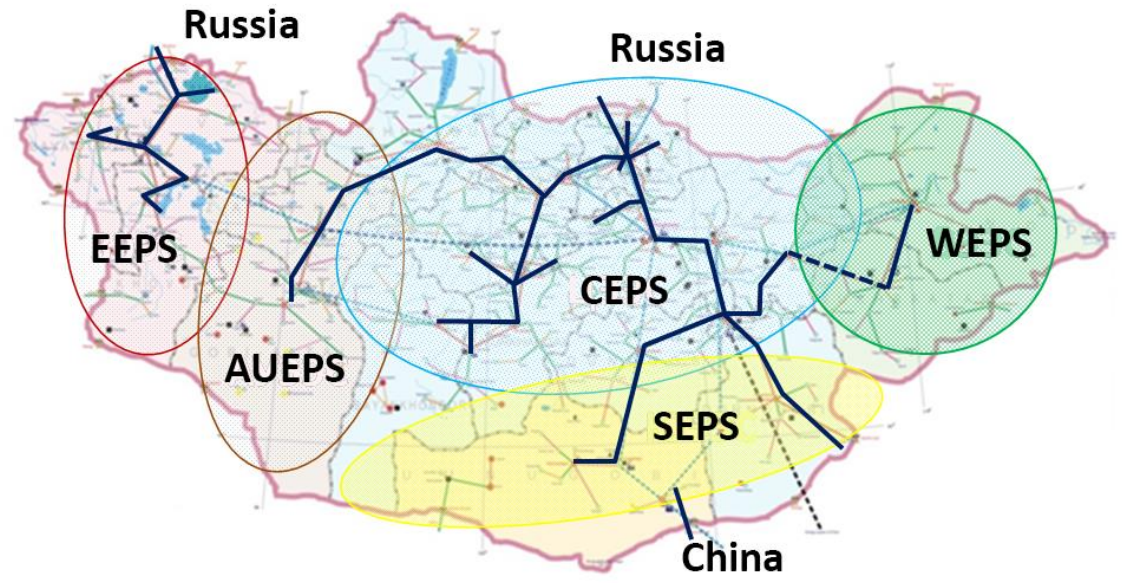

Fig. 1. Geographical position of centralized EPS of Mongolia 
Currently, $80 \%$ of power consumed in the country is produced by thermal power plants (TPP), and $20 \%$ is imported from Russia and China. On the average, $14.4 \%$ of power produced is consumed for auxiliary - Large extension of transmission lines versus relatively low voltage (e.g., one-circuit $700 \mathrm{~km}$ Muren-Telmen $110 \mathrm{kV}$ transmission line);

- Irregularity of daily power consumption (e.g., average annual factor of daily load curve irregularity makes 0.7);

- Obsolete equipment and technologies used by power suppliers and consumers (for example, average period of boilers and turbine generators operation at TPP-4, the largest power plant within CEPS, is 150200 thousand hrs);

- Irrational allocation (concentration) of generating capacities ( $68 \%$ of capacities are located in Ulan-Bator and in its vicinity). needs; power losses in the electric networks average $13.7 \%$. These indicators are 1.3-1.7 times higher than those for countries with developed networks. The main causes are as follows [1-5]:

Centralized power sector in Mongolia in the future should be developed aiming at two interrelated objectives: interconnection of five stand-alone EPS into a Single EPS of the country; integration of Single EPS of Mongolia into the interstate energy grid of Northeast Asia (Fig. 2). Depending on the high or low scenario, development of coal-based generation is proposed at the North-East of the country, construction of large farms of solar and photo-electric power plants is expected in the Gobi desert, and powerful wind mill farms are planned to be constructed predominantly at the East of Mongolia [1-5].

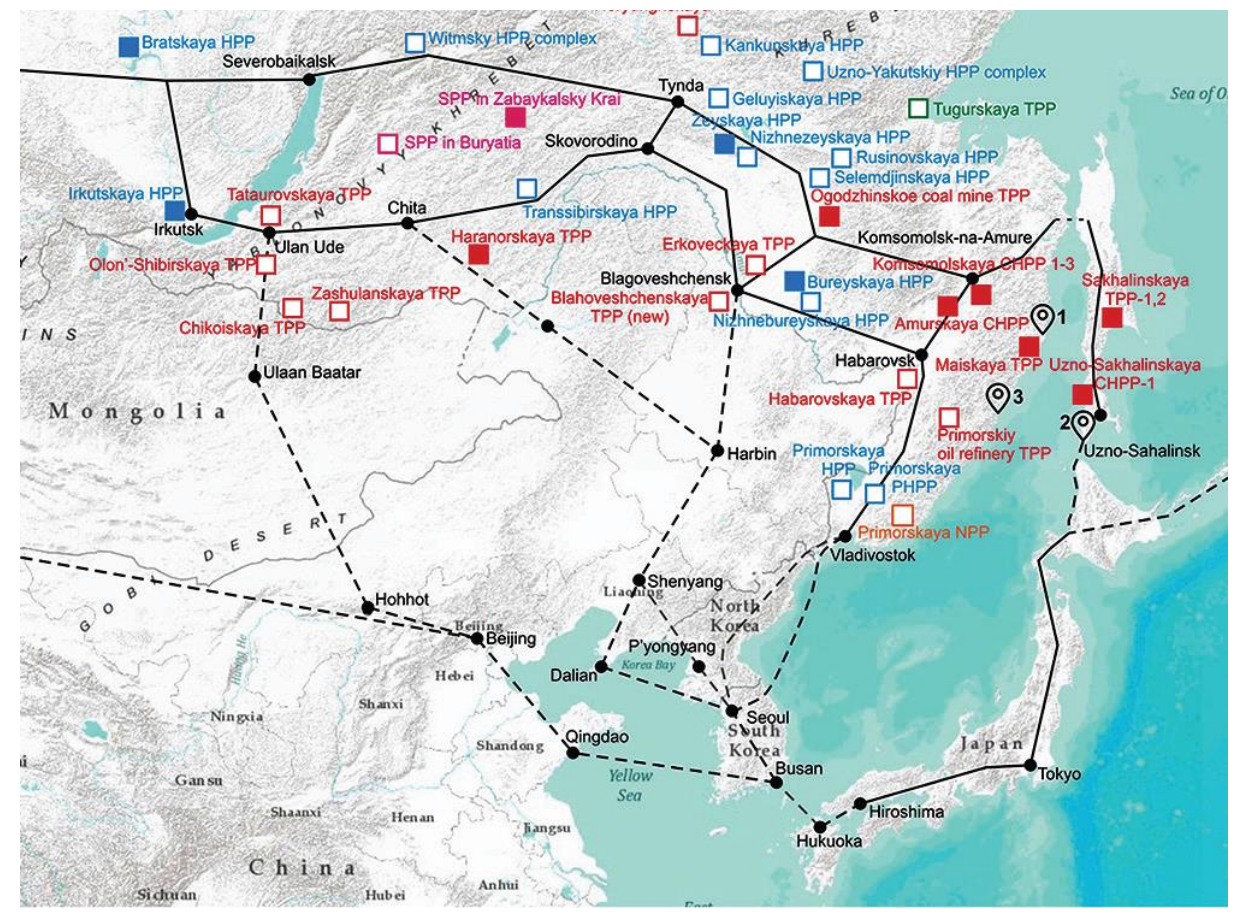

Fig. 2. A chart of and interstate power grid of the Northeast Asia

Small-scale power production has been rapidly developing in Mongolia in recent years. There are in operation 13 mini and micro HPP with the total installed capacity of $28.1 \mathrm{MW}, 17 \mathrm{mini}$ and micro solar power plants (51.6 MW), three (3) mini wind mills (155 MW), seven (7) hybrid microgrids (photo panels and wind mills with or without power storage, 1.275 MW) [8].

Of special interest is a unique Roadmap "100 000 solar photo panels" for creation of DC microgrids for power supply of islanded consumers, whose implementation was financed by the World Bank and governments of Japan and China. The Roadmap realization was started in 2000 and accomplished 12 years after. Owing to implementation of the Roadmap, power was supplied to $70 \%$ of livestock farmers or to about 500000 rural people busy with seasonal grassland farming. Total capacity of photo panels makes 3-4 kW per yurt (a nomads tent). There are also backup photo panels and power storage devices.

Standard mix of electric devices of a yurt of an islanded power consumer at present includes the following: lighting, an electric stove, a refrigerator, an electric heater and a digital TV. Some other electric appliances may surely appear in the nearest future, such as computers, micro ovens, automatic washing machines, and others. Judging from the experience of other countries, a total number of electric appliances in a yurt in the future may exceed 10 names $[10,11]$.

Considerable transformation of structure and functionality of the considered microgrids will take place in the conditions of large-scale use of electro mobiles. In addition, detailed study of benefits and drawbacks of joint use of microgrids (a system of 
microgrids) by several yurts on the relational or contractual base may be of interest.

It is obvious that independent operation of the considered microgrids for islanded consumers distant from centralized power supply will be continued in the future.

\section{Directions and peculiarities of EPS intellectualization in Mongolia}

Taking into account present-day international tendencies, Energy Ministry of Mongolia declared the year 2019 to be a "Year of Intelligent Energy Sector" and proposed a developed state-financed Roadmap of "Intelligent Energy System" whose introduction would improve stability and raise efficiency of Mongolian EPS, and energy security of the country.

Implementation of this Roadmap requires performance of works in three directions:

1) Ensurance of reliable and sustainable operation of EPS in different conditions;

2) Higher economic efficiency of energy sector of the country;

3) Introduction of intelligent systems in the distribution networks and at the level of power consumers.

Analysis of works proposed in the Roadmap within three directions allows the following comments to be given:

a) Creation of Intelligent Energy System (IES) is the systems transformation of energy industry that, judging from experience of other countries [12-14], requires development of conceptual provisions and identification of priorities of IES creation. Meanwhile, according to the Roadmap, development of documentation for construction of IES infrastructure (standards, regulatory documents, etc.) is considered to be a base for EPS intellectualization in Mongolia. Despite the value of standardization documentation, it should be stressed that it shall be developed with view of IES creation concept [7].

b) Large-scale use of wind and solar units in the future would dramatically change the performances of EPS of Mongolia. Those changes would worsen the system controllability in normal conditions since, first, $80 \%$ of power is generated by coal-fired thermal power plants (TPP) operating as per the heating cycle; second, due to random fluctuations in power production by wind mills that are caused by variable wind velocity); it will also raise the problems of EPS stability in emergencies [15].

c) The Roadmap proposed does not give due considerations to peculiarities and problems of intellectualization of microgrids for islanded consumers. Despite relatively small scale of this direction, it is of high social value. Moreover, as it was mentioned above, the implemented national Roadmap "100 000 solar photo panels" did not solve all the problems of power supply for islanded consumers. d) Implementation of the EPS intellectualization program in Mongolia requires training the specialists of new generation, as is noted, for example, in Ref. [16]. This important problem was not given consideration in the Roadmap.

Therefore, it is necessary to develop the concept of forming the intellectual EPS of Mongolia that shall be based on the systems consideration of the existing problems of power industry of the country and directions of its innovative development using intelligent technologies of power production, transmission, distribution and consumption within the fuel and energy complex and with view of integration of EPS of Mongolia into the interstate grid of the Northeast Asia.

Transition to IES is a complex engineering, economic, scientific and organizational problem that implies updating of all the fleet of power (generating, network and consumption) equipment on the innovative base and change over to a new generation of process control and market control systems at all the levels of management and control. With view of the changes in the methods and tools for EPS operation and control, the studies should include three main stages:

- Perfection of automatic control that would ensure faster response of automatic devices and control systems both in emergencies and in normal, transition and operating conditions by using a large specter of emergency control devices, such as stability control schemes, frequency and voltage control devices, etc.

- Better availability of information that would ensure a new level of the EPS conditions observability and monitoring, controllability of operating modes of separate elements and of the system as a whole owing to wider use of digital vector measurements of state variables.

- Introduction of intelligent technologies at all the levels of EPS operation control systems that would ensure both the 'on-line response' and 'forecast response' based on the assessment of probable variations in the parameters of modes of individual devices, systems, and consumers.

Thus, transition to energy of new type shall harmonize all the directions of EPS modernization by expanding the boundaries of an ordinary production process beyond conventional extensive scenario of energy sector development that is characterized by simple quantitative increase of production potential and its saturation with new innovative technologies. It is obvious that intellectualization of microgrids of islanded consumers is of higher availability for implementation than centralized EPS owing to availability of new equipment and lesser complexity and scales of microgrids themselves.

Transition to IES actually implies implementation of an intensive scenario of the energy sector development to be accompanied by functionality change, i.e., transformation of the existing and emergence of new properties in the separate structural segments and in EPS as a whole. 


\section{Conclusions}

The problem of IES creation requires preliminary systems studies of the existing structures and characteristics of EPS of the country that would form a methodological base for development of scientifically grounded concept of transition to a self-actualizing, self correcting system with complex control functions at all the hierarchical levels both for EPS of Mongolia and for power grids for islanded consumers.

To make the future IES of the country meet those requirements, a set of problems need to be solved to rationalize the system structure and update the control systems on the base of digital devices using intellectual technologies. An intellectual Single EPS of Mongolia for its integration into an interstate super grid, i.e., trans-national IEPG of the Northeast Asia, shall be ready to meet additional requirements.

Intellectualization of microgrids of islanded consumers, despite their incomparability with the Centralized EPS of Mongolia in terms of capacity, is of high social importance as microgrids play more and more important role in the total power supply in the specific conditions of the country, and it shall achieve a worthy position in that innovative process.

Creation of IES on the whole shall become a key mechanism in achieving the objectives of the Energy Strategy of Mongolia on transformation of fuel and energy sectors. An intellectual Single EPS of the country shall be converted into high-tech and efficient infrastructure ensuring both quantitative and qualitative economic growth of the country.

\section{References}

1. Bat-Erdene B., Batmunh S., N.I. Voropai, V.F. Stennikov, Some issues of the energy development strategy in Mongolia // Energy Policy, 6, 95-105 (2016)

2. Batmunh S., V.A. Stennikov, Bat-Erdene B., Erdenebaatar A., Potential of Mongolia in the international cooperation of the Asian energy space // Vestnik IrGTU, 21, 10, 65-77 (2017)

3. Batmunh S., V.V. Salomatov, V.A. Stennikov, Enhzhargal H., An environmentally friendly coal-fired TPP and a concept of a multi grid with integration into EPS of Mongolia, Novosibirsk: Geo Publishing House (2019)

4. Batmunkh S., V. Stennikov, Bat-Erdene B., Erdenebaatar A. Mongolia's potential in international cooperation in the Asian energy space // E3S Web of Conferences, 01006 (2018)

5. Bat-Erdene B., Batmunkh S., Erdenebaatar A., Development of power generating sector of Mongolia and its role in creating an international power grid in Northeast Asia // Energy Systems Research, 1, 4, 31 -37 (2018)

6. N.I. Voropai, M.V. Gubko, S.P. Kovalev, L.V. Massel, et al. Problems of development of digital energy in Russia // Problems of Control, 1, 2-14 (2019)

7. Bat-Erdene B., Batmunkh S., N.I. Voropai, Munhtulga D., Enhtur E., State-of-the-art and prospects of intellectual energy development in Mongolia // Vestnik MEI, 3, 11-16 (2020)

8. N.I. Voropai, Bat-Undral B., Enhsaihan E., Directions and problems of microgrids development for islanded consumers in Mongolia // Izvestiya RAN. Energy, 6, 43-50 (2019)

9. Batbayar Ch., Development of renewable energy in Mongolia / Report. Energy Ministry of Mongolia, https:// docplayer.ru $>52253453$ Razvitie-ozobnovl...(2013).

10. Microgrids 1 Engineering, economics, and experience. Capabilities, benefits, business opportunities, and examples. Microgrids evolution roadmap / C. Marnay, C. Abbey, G. Joos, e.a. // Electra, 283, $71-75$ (2015)

11. Microgrids: Architectures and control / Edited by N.Hatziargiriou. N.Y.: IEEE Press-Wiley, (2014)

12. Grid 2030: A national version for electricity's second 100 years. Office of Electric Transmission and Distribution. United States Department of Energy, (2003)

13. European smart grids technology platform: Vision and strategy for Europe's electricity networks of the future. European Commission, (2006)

14. A concept of a smart electric energy grid of Russia with an active-adaptive network / R.N. Berdnikov, V.V. Bushuev, S.N. Vassiliev, F.V. Vesselov, N.I. Voropai, et al. Edited by Fortov V.E. and Makarov A.A. M.: OJSC FSK EES, (2012)

15. Ch. Ulam-Orgil., Lee Hue-Won, Kang YongCheol. Evaluation of wind power penetration limit and wind energy penetration in the Mongolian central power system // Journal on Electrical Engineering Technologies, 7, 852 858 (2012)

16. Batmunch S., Tserendolgor D.. Training the energy engineers of new generation: current challenges, curriculum review, expected results // Energy \& Engineering, 4 (194), 20-26 (2020) (in Mongolian) 